\title{
CONFLICTS OF PEASANTS IN MARCH-OCTOBER 1917 (BASED ON MATERIALS FROM THE VLADIMIR PROVINCE)
}

(C) 2020

\author{
Ptitsyna Galina Mikhailovna, assistant of Russian History Department \\ Vladimir State University (Vladimir, Russian Federation)
}

\begin{abstract}
This paper presents an analysis of the social behavior of peasants in the Vladimir province in MarchOctober 1917 for their conflicts and highlights the main directions of confrontation. The characteristic of the elaboration of the problem by both Soviet and modern historical science is given. The limited use of statistics on the selected region is explained and the methodological basis of the study is determined. The author considers the conflicts of peasants not only from the side of statistics, but also from the standpoint of individual plots that better reveal everyday behavioral practices. The work describes in detail and group the clash of interests of peasants with the surrounding social reality. The conclusion is drawn about the baselessness of the thesis of the Soviet historiography that the main enemies for peasants were landlords, kulaks and the bourgeois' Provisional Government. The analysis of sources revealed that the peasant commune in March-October 1917, solving its pressing issues of food and land-use, was against all. Its conflicts took place on several directions at once: «city - village», «commune - private owners», «commune - commune» and intra-commune disputes. There were also conflicts with the state, but they were not political.

Keywords: Russian peasantry; Russian revolution of 1917; Vladimir Gubernia; Provisional Government; peasant commune; commune revolution; peasant movement; social behavior; conflicts; provincial society; revolutionary power; historical anthropology; history of everyday life.
\end{abstract}

\section{ИСТОРИЯ НАРОДНЫХ СТРОЕК 1940 ГОДА (НА ПРИМЕРЕ ФЕРГАНСКОЙ ДОЛИНЫ)} (C) 2020

\author{
Насритдинов Кабулжан Махамаджанович, кандидат исторических наук, \\ доцент кафедры гуманитарных наук \\ Андижанский филиал Ташкентского государственного аграрного университета \\ (2. Андижан, Республика Узбекистан)
}

\begin{abstract}
Аннотация. На основе научно-исторических и архивных источников автор статьи анализирует историю выработки планов по орошению целинных земель центральной части Ферганской долины в первой половине XX века крупными русскими учеными, специалистами и показывает историческую картину строительства ирригационных сооружений в Ферганской долине в 1940 году скоростным народным методом «хашар». Со строительством гидротехнических сооружений, таких как Северный и Южный Ферганские каналы, начался новый этап в развитии орошаемого земледелия Ферганской долины, так как воды этих гидротехнических сооружений дали возможность оросить новые целинные земли центральной части и предгорных районов Ферганской долины. Следует отметить, что эти крупные и по своей конструкции сложные оросительные каналы были построены в основном с помощью примитивных орудий труда, таких как кетмень, лом, лопата, носилки, кирки и мешки, благодаря трудовому подвигу народов Узбекистана. Эти гидротехнические сооружения вот уже почти 80 лет обеспечивают сельскохозяйственные районы живительной влагой. Также в статье автор обобщает суть экономических мероприятий, осуществленных Советским правительством по развитию орошаемого земледелия в долине.
\end{abstract}

Ключевые слова: Ферганская долина; земледелие; орошение; русло; акведук; сифон; экстенсивный путь развития; мешок; хашар; кетмень; лопата; лом; кубометр; ирригация; гидротехническое сооружение; мелиорация; предгорный район; канал; гидроузел; строительство; район; правительство; народная стройка; дамба; плотина; проект; хребет; водосброс; гектар; колхоз.

Из исторических источников нам известно, что 1932 году в Советском Союзе была достигнута «хлопковая независимость», так как в хлопкосеющих союзных республиках в 1932 году было выращено 1216617 т хлопка. Доля хлопка, выращенного в Республике Узбекистан, составляла более 758044 т, а в процентном соотношении она равнялась $65 \%$ общего урожая [1, с. 166].

Учитывая это обстоятельство, союзное правительство приняло решение к изысканию возможностей Узбекской Республики в дальнейшем развитии хлопководства. По этому решению правительством была поставлена задача выработать генеральный рабочий план по орошению новых земель Ферганской долины, так как в 30-е годы XX века Ферганская долина была основным хлопкосеющим регионом Республики Узбекистан.

После принятия этого решения на территории всей долины велись комплексные проектно-изыскательские и научно-практические работы по изучению природных возможностей дальнейшего развития хлопководства. В этих комплексных работах, по 
рекомендации Советского правительства, основной упор делался на экстенсивное развитие сельского хозяйства в регионе, конечным результатом должно было стать количество орошаемых земель. Поэтому перед специалистами была поставлена задача изыскать и подготовить проекты по строительству новых каналов для орошения целинных земель центральной Ферганы и предгорных районов долины.

Из исторических научных источников нам известно, что вопросами орошения целинных земель центральной Ферганы, еще начиная с марта 1913 года, по рекомендации имперского правительства России активно занималась проектно-изыскательская партия во главе с инженером Н.Н. Епанчиным [2, c. 136]. Учеными и специалистами по предложению ряда коммерческих компании было подготовлено 6 проектов по орошению Ферганской долины [3, c. 67]. Но из-за политических событий 1917 года эти работы были приостановлены.

В 1929 году разработкой проекта ирригации на Сырдарье, частично по Ферганской области, занималось Сырдарьинское бюро «Средазводхоза» [4, с. 38]. Основу подготовленного бюро проекта составили гидротехнические проекты, разработанные проектно-изыскательской партией, которой руководил инженер-ирригатор Н.Н. Епанчин.

В 1930 году выдвигается новый проект орошения Ферганской долины по схеме Г.К. Ризенкампфа. Эта схема, по сравнению с предыдущими, давала новое направление. Однако все выводы автора были ориентировочными, так как специальных изысканий по изучению Ферганской долины автором не проводилось.

После многократного обсуждения разных проектов, выдвинутых учеными специалистами в 1933 году, был составлен и утвержден генеральный рабочий план по орошению земель Ферганской долины. В соответствии с разработанным планом ставились задачи по регулированию вод горных рек Чаткалского, Ферганского, Алайского, Кураминского и Туркестанского хребтов, которое дало бы возможность максимального использования воды этих рек в дальнейшем развитии сельского хозяйства Ферганской долины. Рабочей группой было рекомендовано построить три канала для орошения целинных земель центральной Ферганы: Большой Ферганский канал общей протяженностью 280 км, Северный Ферганский канал общей протяженностью 160 км, Южный Ферганский канал общей протяженностью 120 км. Строительство этих каналов дало бы возможность оросить целинные земли центральной Ферганы. Кроме этого, по плану намечалось построить сеть водосбросов, таких как Сарикжуга, Ёзёвон, Файзобод, Багдад, Сух-Исфара. Главная задача этих водосбросов заключалась в том, чтобы снизить уровень грунтовых вод самой низкой части Ферганской долины. Характерная особенность центральной Ферганской степи заключалась в том, что уровень грунтовых вод находился очень близко к поверхности земли. Строительство этих гидротехнических сооружений дало бы возможность, во-первых, снизить уровень грунтовых вод; во-вторых, освоить 200 тыс. га новых целинных земель центральной Ферганы [5, c. 163$]$.
Годы третьей пятилетки (1938-1942 годы) вошли в аграрную историю Узбекистана периодом «народных строек». В 1939 году посредством народного метода «хашар» был построен Большой Ферганский канал.

После выработки плана по орошению земель Республики Узбекистан, в частности Ферганской долины, ЦК ВКП(б) и СНК СССР от 22 декабря 1939 года приняли постановление «О мерах по дальнейшему подъему хлопководства в Узбекистане», в котором было предусмотрено, что в течение ближайших шести лет необходимо освоить 430 тыс. га новых орошаемых земель [6, с. 154]. В связи с этим намечалось строительство крупных водохозяйственных объектов в областях республики с активным участием тружеников колхозов. Для этого государство выделило необходимые денежные средства, материалы, оборудование, механизмы и автотранспорт.

Для реализации этого решения правительство Узбекистана 20 января 1940 года приняло специальное постановление «О строительстве Северного Ферганского канала и Южного Ферганского канала» [6, с. 51].

Проектно-изыскательские работы Северного Ферганского канала проводились во главе с инженером Института «Сазводпроиз» В.Н. Симаковым при участии инженеров-гидротехников А. Тюленева, А. Кузнецовой [7, л. 6-7]. Согласно проекту длина Северного Ферганского канала составляла 163 км. Воды канала позволили бы обеспечить 19 тыс. га новых земель в Уйчинском, Янгикурганском, Наманганском, Туракурганском, Касансайском и Папском районах Республики Узбекистан и Аштском районе Республики Таджикистан, что улучшило бы водоснабжение 66732 га староорошаемых земель, кроме этого, резко ускорило бы экономическое развитие таких отраслей сельского хозяйства, как бахчеводство и садоводство, расположенных на правом берегу реки Сырдарья [8, с. 7]. Пропускная способность канала составляет $100 \mathrm{~m}^{3}$ воды в секунду, причем начальные 61 км русло нового канала должно было пройти по руслам уже существующих каналов Янгиарык и Розенбах. Оставшиеся 102 км планировалось построить в предгорьях Наманганского оазиса [9]. Предусматривалось, что канал берет воду из реки Нарын и достигает Камышкурганской степи в Аштском районе Республики Таджикистан. Проект канала был рассчитан так, что он 144 км пройдет по территории Узбекистана, а 18,5 км - по территории Республики Таджикистан. Чтобы построить этот канал, ежедневно на строительстве русла должны были участвовать от 80000 до 100000 колхозников, которым надо было выполнить земляные работы в объёме 6 млн м ${ }^{3}$ и построить 48 крупных ирригационных сооружений [8, c. 16-17]. Главным инженером строительства был назначен Д.К. Терситский [10, с. 192].

Русло строящегося канала был разделено на 20 строительных участков, где земляные работы начались с 10 февраля 1940 года. Трудящиеся Попского, Уйчинского, Косонсойского, Янгикурганского, Наманганского и Туракурганского районов вышли первыми на строительство [10, с. 165]. В первый день в строительстве работало 38-40 тыс. чел. На следующий день в помощь строителям канала приехали колхозники из районов Учкурган и Избаскан, Балик- 
чи и Пахтаабад, которые взяли на себя обязательство выполнить 1 млн м³ земляных работ [10, с. 165].

В строительстве канала ежедневно принимало участие в среднем 90 тыс. чел. Следуя руководящим принципам «народных строек», все русло канала разделили на 20 участков, которые, в свою очередь, были распределены на колхозы, колхозные участки были разделены на бригады, а бригады - на звенья. Каждое звено состояло из трех человек: один копал землю, а двое других выносили землю на обочину. У каждого звена было по три кетменя, двое носилок, одна кирка. Орудия труда, как видно из этого, не позволяли говорить о высокой производительности труда. Лишь высокая самоотдача людей и их патриотизм были достойны всяческого уважения.

Земляные работы на русле строящегося Северного Ферганского канала продолжались в течение 35 дней. Общий объем выполненных земляных работ составил $5382109 \mathrm{~m}^{3}$. На выполнение поставленных задач было потрачено 2358,4 тыс. трудодней [10, c. 167]. Проектная стоимость строительных работ, выполненных на русле канала, оценивалась в 35025 тыс. рублей. При строительстве канала было использовано $2358 \mathrm{t}$ цемента, $1445 \mathrm{~m}^{3}$ древесины, 498,5 т железа и других строительных материалов. В ходе строительства канала были реконструированы 10 старых гидротехнических сооружений, построено новых 4 акведука, 6 дюкеров, 40 маленьких деревянных водяных лотков, 17 инженерных водораспределителей. Среди них самые большие сооружения железобетонный дюкер на Резаксае и железобетонный акведук на Жанжалсае. Русло канала пересекло 20 селевых саев, речек и оврагов, через которые были построены железобетонные сооружения. На строительстве Северного Ферганского канала работали 620 инженеров, которые руководили выполнением земельных работ. Вода на русле Северного Ферганского канала была открыта 23 июля 1940 года и впервые воды реки Нарын пришли на орошение предгорных земель земледельческих районов Уйчи, Янгикурган, Наманган, Туракурган, Касансай и Пап Республики Узбекистан, а также Аштского района Республики Таджикистан. Строительство канала дало возможность освоить и оросить 19 тыс. га новых земель, из которых 5590 га новых земель с водами реки Нарын Камышкурганской степи Республики Таджикистан [11, с. 75].

Вторым крупным ирригационным сооружением, построенным в 1940 году в Ферганской долине, является Южный Ферганский канал. Проект канала был составлен научными сотрудниками института «Сазводпроиз» под руководством инженера Б.А. Мехельсона $[10$, с. 192]. По проекту русло канала должно было пройти по руслу Кувинской ветки, подпитывающейся из Шарихансая и построенной в 19351936 годах. Кувинская ветка обеспечивала орошаемые земли низовых частей маловодной Араванской и Исфайрам-Шахимарданской оросительных систем водой Карадарьи [12, с. 48]. В 1940 году Кувинская ветка была продлена до Маргелансайской ветки и было построено новое русло канала из Аравансая до Кувасая. Таким образом, новый построенный канал получил название Южный Ферганский канал. Земляные работы на строительстве нового канала начались
16 февраля 1940 года. Общий объем земляных работ в 2,4 млн м ${ }^{3}$ выполнен за 57 дней при участии 48 тыс. колхозников из 890 колхозов 12 районов Ферганской области с общей затратой труда 1,5 млн человекодней. На русле канала построено 151 гидротехническое сооружение, в том числе 1 акведук, 16 дюкеров, выполнено бетонных и железобетонных работ $7116 \mathrm{~m}^{3}$, каменных $-10782 \mathrm{~m}^{3}$, деревянных $-800 \mathrm{~m}^{3}$ [10, с. 192]. Канал был сооружен за 57 дней [13, c. 61]. Во время строительства канала участников обслуживали 168 работников медицины, 1310 сотрудников торговли, 500 артистов. Главным инженером строительства был А.И. Ронкин. В результате строительства Южного Ферганского канала была повышена водообеспеченность орошаемых земель на площади 66 тыс. га, увеличены площади садов и виноградников на 5880 га, тутовников на 300 га и было освоено 6937 га новых земель [10, с. 192].

В заключение следует отметить, что в 1940 году в результате проявленного трудового подвига народов Узбекистана по всей республике были построены десятки крупных гидротехнических сооружений, в строительстве участвовало более 1,5 млн чел., которые выполнили работу на 280 млн рублей. Только в Ферганской долине было освоено 50 тыс. га новых земель. По всей республике общий объем орошаемых земель в 1940 году достиг 2130 тыс. га [14, л. 14].

\section{Список литературы:}

1. Раззаков А. История хлопководства Узбекистана (на узбекском языке). Ташкент: Узбекистан, 1994. $302 \mathrm{c}$.

2. Жалилов С. Из истории орошения земель Ферганской долины (на узбекском языке). Ташкент: Фан, 1977. $166 \mathrm{c}$.

3. Зиёев Х. Узбекистан под прессом гнета и колониальности (на узбекском языке). Ташкент: Шарк, 2006. $352 \mathrm{c}$.

4. Абдулхамидов А. Из истории орошения Кокандского оазиса. Ташкент: Фан, 1974. 76 с.

5. Мамедов А.М. Развитие ирригации в Узбекистане. Ташкент: Фан, 1967. 173 с.

6. Коммунистическая партия Узбекистана в резолюциях. Т. 2. Ташкент: Узбекистан, 1988. 912 с.

7. Центральный государственный архив Республики Узбекистан (ЦГА РУз). Ф. 2510. Оп. 1. Д. 447.

8. Хачикянц С.П. Северный Ферганский канал // Социалистическое сельское хозяйство Узбекистана. 1940. № 3. С. 6-19.

9. Схематическая карта Северного Ферганского канала // Альбом САНИИРИ. 1940. № 2. С. 36.

10. Ирригация Узбекистана. Т. І. Ташкент, 1975. $354 \mathrm{c}$

11. Насритдинов К.М. История орошения Ферганской долины (на узбекском языке). Ташкент: Янги аср авлоди, 2009. 224 с.

12. Касымов Ю. История орошения наманганского оазиса (на узбекском языке). Ташкент: Фан, 1988. $122 \mathrm{c}$.

13. Халиков И., Эшчанов К., Алимов И. Осуществление ленинских идей орошения в Средней Азии. Ташкент: Укитувчи, 1986. 248 с.

14. ЦГА РУз. Ф. 2483. Оп. 1. Д. 69. 


\title{
THE HISTORY OF NATIONAL CONSTRUCTIONS OF 1940 (BY THE EXAMPLE OF THE FERGHANA VALLEY)
}

(C) 2020

\author{
Nasritdinov Kabulzhan Makhamadzhanovich, candidate of historical sciences, \\ associate professor of Humanities Department \\ Andijan Branch of Tashkent State Agrarian University (Andijan, Republic of Uzbekistan)
}

\begin{abstract}
Based on scientific, historical and archival sources the author of the paper analyzes the history of developing plans aimed at irrigation of virgin lands in the central part of the Ferghana Valley in the first half of the $20^{\text {th }}$ century by large Russian scientists and specialists. The author also shows a historical picture of the construction of the irrigation facilities of the Ferghana Valley using the high-speed «hashar» folk method in 1940. With the construction of hydraulic structures such as the northern and southern Ferghana canals, a new stage began in the development of irrigated agriculture in the Ferghana Valley, since the water of these hydraulic structures made it possible to irrigate new virgin lands in the central part and foothill areas of the Ferghana Valley. But it should be noted that these large and complex irrigation canals were constructed by the peoples of Uzbekistan mainly with the use of primitive tools such as a hoe, a crow, a shovel, a stretcher and pickaxes. For nearly 80 years, these hydraulic structures have provided agricultural areas with life-giving water. The author of the paper also summarizes the essence of economic measures carried out by the Soviet government on the development of irrigated agriculture in the valley.

Keywords: Ferghana Valley; agriculture; irrigation; riverbed; aqueduct; siphon; extensive development path; bag; «hashar»; hoe; shovel; crow; cubic meter; irrigation; waterworks; land reclamation; foothill; canal; waterworks; construction; district; government; national construction; dam; project; ridge; spillway; hectare; collective farm.
\end{abstract}

$* * *$

УДК 94 (73)

DOI 10.24411/2309-4370-2020-11212

Статья поступила в редакцию 08.11 .2019

\section{СОВЕТСКАЯ ШКОЛЬНАЯ СИСТЕМА В ОЦЕНКАХ ЦРУ НА ПЕРВОНАЧАЛЬНОМ ЭТАПЕ ХОЛОДНОЙ ВОЙНЫ}

(C) 2020

Мамедов Заур Ималверди оглы, аспирант кафедры всеобщей истории, права и методики обучения Самарский государственный социально-педагогический университет (2. Самара, Российская Федераџия)

Аннотащия. Статья посвящена анализу школьной системы СССР Центральным разведывательным управлением. США остро нуждались в информации о своём новом противнике. Ситуация усугублялась закрытостью Советского государства и отсутствием длительной непрерывной традиции разведывательной деятельности американской разведки. Президент и другие органы государственной власти хотели иметь всестороннюю осведомленность о любых процессах и явлениях в мире. Американская разведка должна была быть в состоянии решить эту задачу. В связи с этим первый этап холодной войны для ЦРУ в большей степени основывался на анализе официальных и полуофициальных источников, а также на выработке различных стратегий. Для того чтобы узнать о различных сферах жизни СССР, аналитики извлекали информацию из советской научной литературы, прессы, радио, законодательства и допросов бывших немецких пленных. Бюро национальных оценок во главе с Уильямом Лангером и Шерманом Кентом составляло отчёты о советском военном потенциале, промышленности, сельском хозяйстве, политической системе и многом другом. Советская школьная система рассматривалась специалистами американской разведки в рамках военного и экономического потенциала противника, а также стратегии психологической войны. В статье проанализированы рапорты, касающиеся системы образования в СССР в аспекте школьного обучения, его сильных и слабых сторон. Полученные результаты позволяют сделать вывод о том, что информация о советской школьной системе способствовала формированию внешнеполитического и внутриполитического курса США.

Ключевые слова: ЦРУ; США; СССР; холодная война; американская разведка; школьная система; психологическая война; Советский Союз; система образования; Сталин; Трумэн; Уолтер Беделл Смит; Шерман Кент; Уильям Лангер; Роберт Бирнс; Бюро национальных оценок; просвещение; военный потенциал; образовательная политика.

Хронологические рамки исследования затрагивают начальный этап холодной войны с образования ЦРУ в 1947 году и до смерти Сталина в 1953 году, как смены политического управления в СССР. Комплексных исследований, посвященных аналитической работе Центрального разведывательного управления по Советскому государству в этот период, нет. Есть отдельные работы, в которых изучались различные события, явления, процессы, связанные с CССР, на основе архивных данных американской разведки. К таким относятся статьи Д.В. Суржика, в которых, благодаря рассекреченным документам проекта «Цезарь», автору удалось определить последствия так называемого дела врачей [1, с. 78] и проанализировать ряд других внутриполитических процессов в СССР [2, с. 33]. О внутрипартийной борьбе также пишет С.О. Буранок, в работе которого прослеживается вывод о частичной зависимости молодой разведывательной организации от более опытных ведомств, в частности ФБР [3, с. 61]. А.С. Крым- 